\title{
Self-Healing Coatings for Corrosion Inhibition of Metals
}

\author{
Akihiro Yabuki ${ }^{1}$ \\ ${ }^{1}$ Department of Chemical Engineering, Faculty of Engineering, Hiroshima University, 1-4-1 Kagamiyama, \\ Higashi-Hiroshima 739-8527, Japan \\ Correspondence: Akihiro Yabuki, Department of Chemical Engineering, Faculty of Engineering, Hiroshima \\ University, 1-4-1 Kagamiyama, Higashi-Hiroshima 739-8527, Japan. E-mail: ayabuki@hiroshima-u.ac.jp
}

Received: May 4, 2015

Accepted: June 5, 2015

Online Published: June 30, 2015

doi:10.5539/mas.v9n7p214

URL: http://dx.doi.org/10.5539/mas.v9n7p214

\begin{abstract}
Anti-corrosion protective coatings have been widely applied as a surface treatment to prevent corrosion of various metallic materials, such as aluminum alloys, magnesium alloys, steel and zinc-coated steel, which are used in automobile parts, building structures, home appliances, etc. One of the most important characteristics of these coatings is the ability to self-heal. If a self-healing coating suffers mechanical damage and corrosive species in the environment begin to degrade the bare metal surface, the damaged surface is automatically repaired by a chemical component of the coating. Chromate conversion coatings have self-healing properties. However, environmental concerns have necessitated the reduction and discontinuation of chromate-based protective coatings in recent years. This paper describes two recently developed self-healing coatings - a fluorine polymer coating with metal particles and a coating comprised of particles and an organic healing agent. A fluorine polymer coating has self-healing properties, which are improved by the addition of metal particles. A self-healing coating that uses particles and an organic healing agent has also been developed.
\end{abstract}

Keywords: self-healing, coating, corrosion, metal, polymer, particle

\section{Introduction}

Metallic materials have been widely used in many engineering fields. However, the long-term durability and reliability of metallic materials are still problematic when they are used in structural applications. Exposure to a harsh environment easily leads to the dissolution of metallic ions. Microcracking is one type of fatal damage that occurs during manufacturing or use. It can cause catastrophic material failure and, hence, significantly shorten the lifetime of a structure. Because damage deep within a material is particularly difficult to identify and repair, materials that have self-healing properties are desirable. In fact, there are many examples of self-healing materials in biology (Trask, 2007; Hastings \& Mahmud, 1993; Martin, 1997; Albert \& Wong, 1991). For example, in the case of a skin wound, the defect is temporarily plugged with a fibrin clot, which is infiltrated by inflammatory cells, fibroblasts, and a dense capillary plexus of new granular tissue. Inspired by these naturally occurring prototypes, considerable effort is being devoted to the development of materials that mimic those found in nature. In particular, integration of self-healing properties into anti-corrosion protective coatings for metallic materials is a focus of ongoing research (Figure 1).

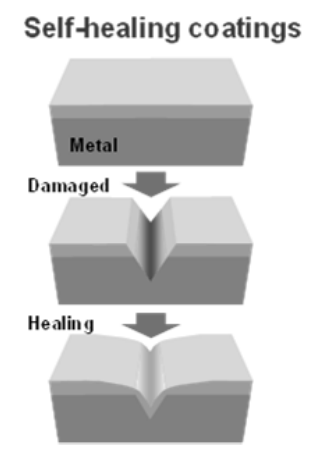

Figure 1. Process by which anti-corrosion protective self-healing coatings for metallic materials undergo self-repair 
Chromate conversion coatings have been widely applied as a surface treatment to prevent corrosion of various metallic materials. Chromate conversion coatings have excellent anti-corrosion properties. Moreover, they are cheap and the solutions used for coating are easy to prepare. An important characteristic required for these types of coatings is the ability to self-heal, so that a film on the surface of a material is automatically repaired if damaged. Environmental concerns, however, have necessitated the reduction and discontinuation of chromate-based coatings in recent years. A trivalent chromate conversion coating has been applied as an alternative to hexavalent chromate conversion coatings (Sandrine et al., 2005; Magalhaes et al., 2004; Buchheit et al., 2003; Song \& Mansfeld, 2006; Palanivel et al., 2005; Zheludkevich et al., 2005; Trabelsi et al., 2005).

Based on previously published studies of self-healing materials, self-healing, anti-corrosion protective coatings for metallic materials were developed. Aluminum alloys and magnesium alloys were used as the substrates for coating, since these light, ecologically appropriate materials are used in automobile and aircraft manufacturing. Two types of self-healing coatings will be described: self-healing polymer coatings and the effects of metal particles on these coatings; and particle-based coatings, which are environmentally friendly self-healing materials.

\section{Self-Healing Polymer Coatings and the Effects of Metal Particles (Yabuki et al., 2007)}

Aluminum alloys are used in compact heat exchangers because of their high thermal conductivity, high specific strength to weight ratio and good corrosion resistance (Lin et al., 1992; Beck \& Kruger, 1996; Poulain et al., 1996; Fedrizzi et al., 1997). Heat exchangers are used in air separation plants, ethylene plants and LNG plants that are operated at very low temperature and in a clean environment. If the unit is used in a seawater environment, corrosion of the aluminum alloy in the unit must be prevented, since the material is susceptible to corrosion by chloride ions. Several methods are currently available for preventing the corrosion of aluminum alloys, such as anodic oxidation, cathodic protection, and the use of inhibitors and protective coatings, etc. Protective coatings are suitable for use in a heat exchanger, since the seawater passes through the unit only once. Several reports have described the use of polymer coatings to protect aluminum and aluminum alloys against corrosion (Uehara et al., 1998; Tallman et al., 2000; Tallman et al., 2002). The desirable properties of such coatings include barrier and self-healing properties.

Several types of coatings that were designed to improve the resistance of aluminum alloys to corrosion in seawater were examined. A 30- $\mu$ m-thick coating was applied to the surface of the aluminum alloy 3003 . After creating an artificial defect in the alloy using a knife-edge, a corrosion test was carried out in $3 \% \mathrm{NaCl}$ at $70{ }^{\circ} \mathrm{C}$ and at a $\mathrm{pH}$ of 1.5 . The polarization resistance of the specimen was determined using an electrochemical impedance method.

The surfaces of the coatings after a 120-h immersion test are shown in Figure 2. Pitting occurred on the portions coated with either a hybrid sol-gel and ceramic coating or a silicon resin coating (right panel of Figure 2). A sol-gel ceramic coating-hybrid type with a curing agent (SGC-HY-C) and a fluorine resin coating (FLR) were damaged in the region with no defect, and were slightly damaged at the defect (left panel of Figure 2).

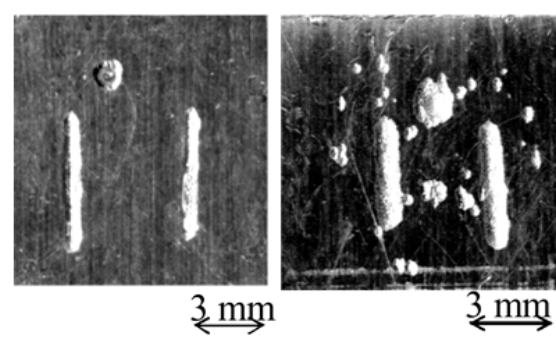

Figure 2. Surface appearances of coatings with an artificial defect after a 120-h immersion test: typical appearance of a sol-gel ceramic coating-hybrid type with a curing agent and a fluorine resin coating (left panel); typical appearance of a sol-gel ceramic coating-hybrid type and a silicon resin coating (right panel)

The self-healing performance of the coatings was evaluated based on the corrosion behavior of the defect. The maximal depth of the deep ditch on a coating was measured both before and during the test using an optical micrograph, and the change in depth was calculated from these data. A specimen with only a deep ditch was prepared for the electrochemical measurements. The polarization resistance of the specimen was determined using an electrochemical impedance method, as shown in Figure 3. The impedances of the coatings were measured in a corrosion test solution using a platinum counter electrode and an SCE reference electrode 
connected to a potensiostat, a frequency response analyzer, and a personal computer. Sine wave voltages $(10 \mathrm{mV}$ $\mathrm{rms}$ ) at frequencies ranging from $20 \mathrm{kHz}$ to $10 \mathrm{mHz}$ were superimposed on a given electrode potential. A computer software program was used to control the measurements. The impedance measured at low frequencies was determined as the polarization resistance to monitor the defect in the specimen. The polarization resistance ratio, which was normalized to the polarization resistance at $1 \mathrm{~h}$, was used for comparison, because the polarization resistance of each coating was different due to differences in the shape and the size of the defect created in the coating before the start of the corrosion test.

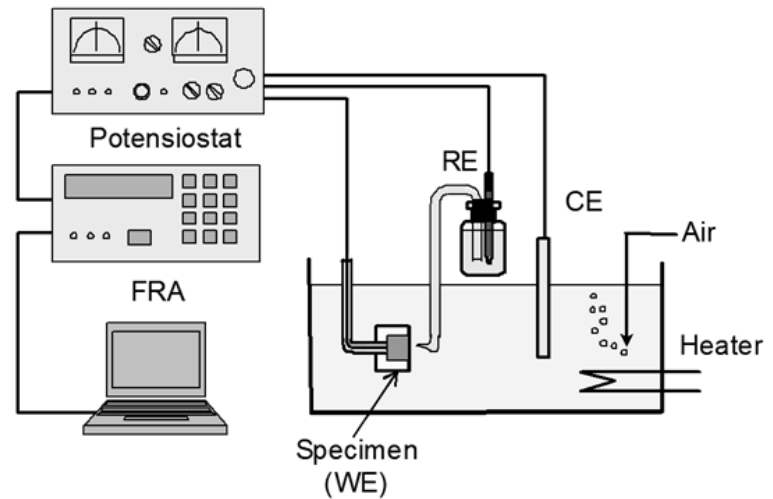

Figure 3. Schematic diagram of the electrochemical impedance measurement system

To examine the surface condition of the defect for SGC-HY-C and FLR, the polarization resistance was measured using an electrochemical impedance method. The ratios for SGC-HY-C and FLR are shown in Figure 4. The polarization resistance ratio of SGC-HY-C decreased approximately linearly with testing time. The ratio of FLR decreased to the same extent as SGC-HY-C up to $80 \mathrm{~h}$, and it increased after $100 \mathrm{~h}$. This difference between the coatings might have been due to the formation of an anti-corrosion protective film consisting of aluminum and fluorine components on the defect.

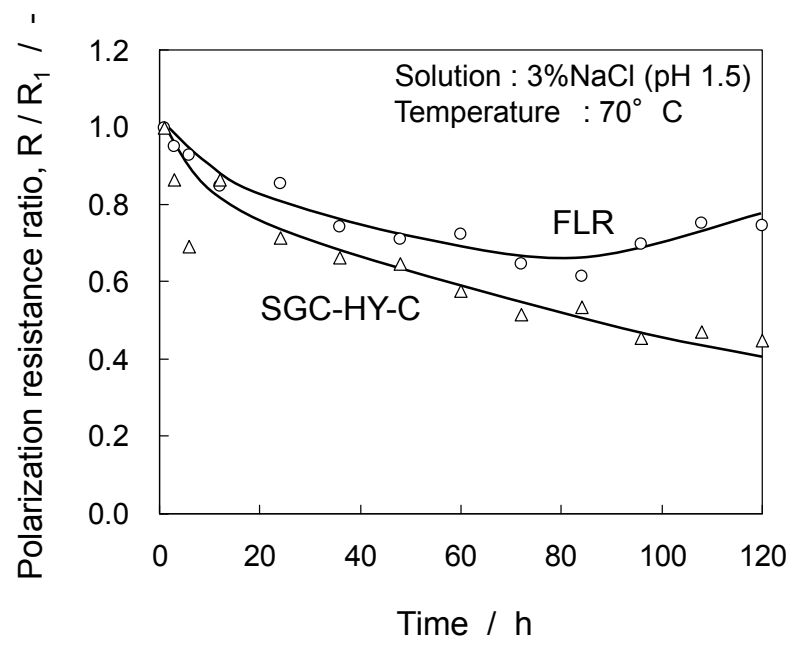

Figure 4. Polarization resistance ratio for a coated specimen during the corrosion test: a sol-gel ceramic coating-hybrid type with a curing agent (SGC-HY-C) and a fluorine resin coating (FLR)

To evaluate the dissolution of the components of FLR, the mass loss of an FLR chip (surface area of $20 \mathrm{~cm}^{2}$ ) was measured in the corrosion test solution. The rate of loss of mass was greatest during the early phase of the immersion test, but it declined after $50 \mathrm{~h}$. This result suggests that a coating ingredient dissolved from the surface of the coating early in the process. A bare aluminum alloy was placed in a solution of the FLR components to examine the anti-corrosion effects of FLR. The loss of mass was less than that of only the test solution. This result indicates that a component of the FLR inhibits corrosion. In other words, FLR has self-healing properties. 
To improve the protective film that formed on the defect, metal powders were added to the FLR. The polarization resistance ratios of these specimens are shown in Figure 5. The depth of the defect in the FLR with a metal powder was less than that with no additive. The polarization resistance ratio decreased, similar to FLR with no additive early in the process, but then increased rapidly after $20 \mathrm{~h}$. The addition of Ti powder to FLR resulted in an excellent anti-corrosion performance. Thus, the self-healing performance of FLR was improved by the addition of metal powders.

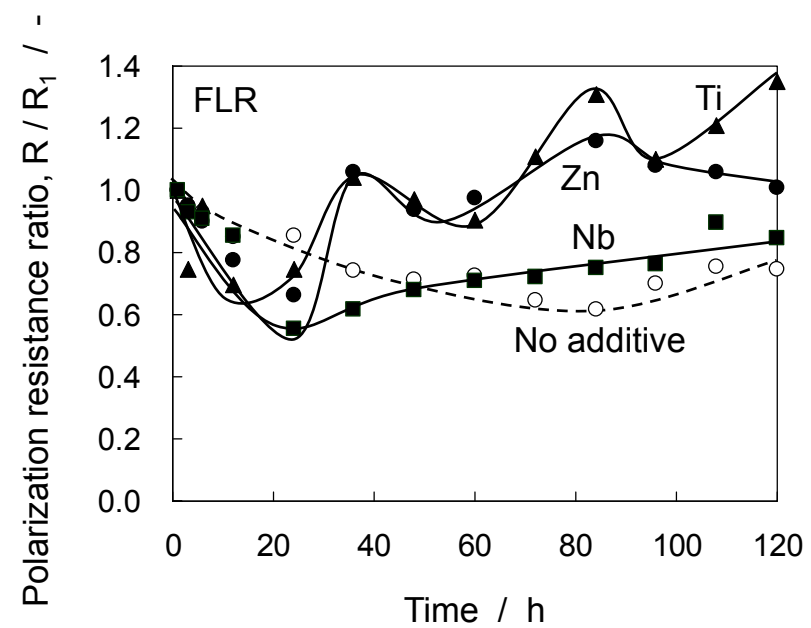

Figure 5. Polarization resistance ratio for the fluorine resin coating (FLR) with added metal particles

\section{Self-Healing Coatings That Use Particles and Organic Healing Agents (Yabuki \& Sakai, 2011)}

Magnesium and its alloys have many excellent properties, such as the lowest densities among industrial metals. Poor resistance to corrosion, however, limits the application of these materials in corrosive environments (Makar \& Kruger, 1990; Song et al., 1997; Ambat et al., 2000; Song et al., 1999). Thus, protective coatings with improved resistance are needed. A self-healing anti-corrosion protective coating was developed for the environmentally friendly magnesium alloy AZ31 (Mg 96.3\%, Al 2.8\%, $\mathrm{Zn} 0.81 \%)$. The coating included $\mathrm{TiO}_{2}$ particles and casein as a pH-sensitive organic agent (Figure 6).

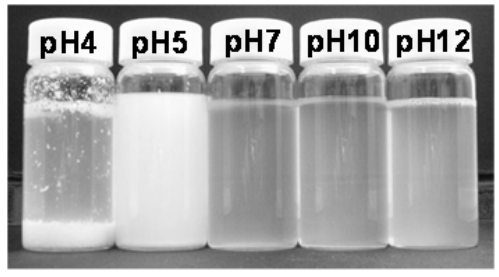

Figure 6. Organic healing agent used for self-healing coatings

A magnesium alloy plate was dip-coated in $\mathrm{TiO}_{2}$ particles, followed by immersion in a casein solution with a $\mathrm{pH}$ of 12 . The $\mathrm{pH}$ of the casein solution was adjusted by the addition of acid to fix the casein in the $\mathrm{TiO}_{2}$ film (Figure 7).

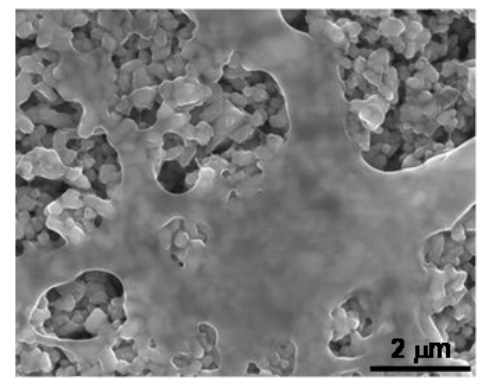

Figure 7. Surface appearance of a coating comprised of particles and an organic healing agent 
After using a knife-edge to create an artificial defect in the coating, a corrosion test was carried out in a $\mathrm{NaCl}$ solution at $35{ }^{\circ} \mathrm{C}$. The self-healing properties of the film were evaluated by monitoring the polarization resistance of the scratched specimen in the corrosive solution and observing the surface appearance of the specimen after the corrosion test. After changing the $\mathrm{pH}$ of the solution from 12 to 5, casein micelles with a mean diameter of 3-4 $\mu \mathrm{m}$ were observed on the surface of the $\mathrm{TiO}_{2}$ film. The polarization resistance of the scratched specimen in the corrosive solution increased with testing time, and a film consisting of $\mathrm{TiO}_{2}$ particles and casein was observed after the test. Thus, the self-healing properties of the coating were confirmed. The self-healing capacity of the coating appeared to be due to the release of casein micelles and $\mathrm{TiO}_{2}$ particles as a result of the increase in $\mathrm{pH}$ that resulted from both the cathodic reaction during corrosion and the formation of a film on the defect (Figure 8).

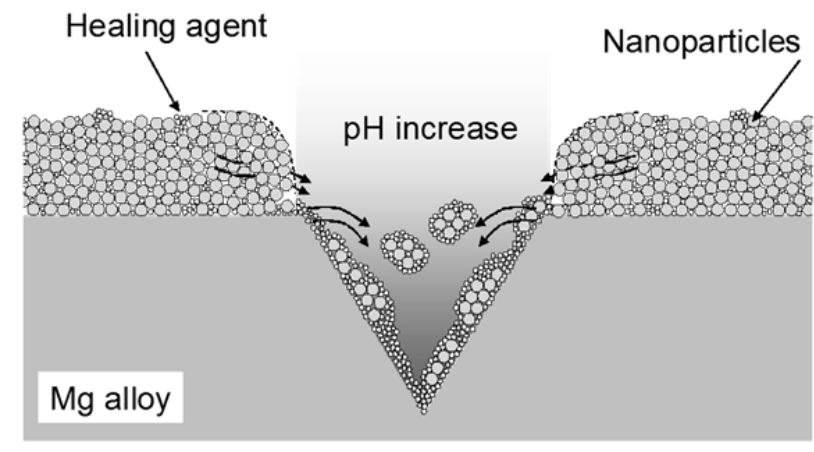

Figure 8. Mechanism by which the particles and the organic healing agent coating undergoes self-healing

\section{Summary}

Environmentally friendly self-healing coatings are desirable alternatives to chromate conversion coatings. Additional development of materials with self-healing properties will reduce the loss that results from corrosion of the metallic materials that are used in chemical plants, automobile parts, building structures, and home appliances. Nanoparticles are effective as a self-healing material, and it is expected that nanoparticles will be successfully applied to anti-corrosion protective coatings.

\section{References}

Albert, S. F., \& Wong, E. (1991). Electrical stimulation of bone repair. Clinics in Podiatric Medicine and Surgery, $8,923-935$.

Ambat, R., Aung, N. N., \& Zhou, W. (2000). Evaluation of microstructural effects on corrosion behaviour of AZ91D magnesium alloy. Corros. Sci., 42, 1433-1455. http://dx.doi.org/ 10.1016/S0010-938X(99)00143-2

Beck, F., \& Kruger, U. A. (1996). EIS of cathodically deposited wet paint films prior to the stoving process. Electrochim. Acta, 41, 1083-1092. http://dx.doi.org/ 10.1016/0013-4686(95)00441-6

Buchheit, R. G., Guan, H., Mahajanam, S., \& Wong, F. (2003). Active corrosion protection and corrosion sensing in chromate-free organic coatings. Prog. Org. Coat., 47, 174-182. http://dx.doi.org/ 10.1016/j.porgcoat.2003.08.003

Fedrizzi, L., Deflorian, F., \& Bonora, P. L. (1997). Corrosion behaviour of fluotitanate pretreated and painted aluminium sheets. Electrochim. Acta, 42, 969-978. http://dx.doi.org/ 10.1016/S0013-4686(96)00274-5

Hastings, G. W., \& Mahmud, E.A. (1993). Intelligent orthopaedic materials. Journal of Intelligent Material Systems and Structure, 4, 452-457. http://dx.doi.org/10.1177/1045389X9300400402

Lin, S., Shih, H., \& Mansfeld, F. (1992). Corrosion protection of aluminum alloys and metal matrix composites by polymer coatings. Corros. Sci., 33, 1331-1349. http://dx.doi.org/ 10.1016/0010-938X(92)90176-4

Magalhaes, A. A. O., Margarit, I. C. P., \& Mattos, O. R. (2004). Molybdate conversion coatings on zinc surfaces. J. Electroanal. Chem., 572, 433-440. http://dx.doi.org/10.1016/j.jelechem.2004.07.016

Makar, G. L., \& Kruger, J. (1990). Corrosion studies of rapidly solidified magnesium alloys. J. Electrochem. Soc., 137, 414-421. http://dx.doi.org/ 10.1149/1.2086455s

Martin, P. (1997). Wound healing-aiming for perfect skin regeneration. Science, 276, 75-81. http://dx.doi.org/ 


\section{$10.1126 /$ science. 276.5309 .75}

Palanivel, V., Huang, Y., \& Ooij, W. J. (2005). Effects of addition of corrosion inhibitors to silane films on the performance of AA2024-T3 in a $0.5 \mathrm{M} \mathrm{NaCl}$ solution. Prog. Org. Coat., 53, 153-168. http://dx.doi.org/ 10.1016/j.porgcoat.2003.07.008

Poulain, V., Petitjean, J. P., Dumont, E., \& Dugnoille, B. (1996). Pretreatments and filiform corrosion resistance of cataphoretic painted aluminium characterization by EIS and spectroscopic ellipsometry. Electrochim. Acta, 41, 1223-1231. http://dx.doi.org/10.1016/0013-4686(95)00474-2

Sandrine, D., Maurin, G., Nogueira, R. P., Persello, J., \& Pommier, N. (2005). Silica-based coating for corrosion protection of electrogalvanized steel. Surf. Coat. Technol., 194, 363-371. http://dx.doi.org/ 10.1016/j.surfcoat.2004.07.126

Song, G., Atren, A., John, DSt., Wu, X., \& Nairn, J. (1997). The anodic dissolution of magnesium in chloride and sulphate solutions. Corros. Sci., 39, 1981-2004. http://dx.doi.org/ 10.1016/S0010-938X(97)00090-5

Song, G., Atrens, A., \& Dargusch, M. (1999). Influence of microstructure on the corrosion of diecast AZ91D. Corros. Sci., 41, 249-273. http://dx.doi.org/10.1016/S0010-938X(98)00121-8

Song, Y. K., \& Mansfeld, F. (2006). Development of a Molybdate-Phosphate-Silane-Silicate (MPSS) coating process for electrogalvanized steel. Corros. Sci,. 48, 154-164. http://dx.doi.org/ 10.1016/j.corsci.2004.11.028

Tallman, D. E., Pae, Y., \& Bierwagen, G. P. (2000). Conducting Polymers and Corrosion: Part 2 - Polyaniline on Aluminum Alloys. Corros,. 56, 401-410. http://dx.doi.org/10.5006/1.3280544

Tallman, D. E., Vang, C., Wallace, G. G., \& Bierwagen, G. P. (2002). Direct electrodeposition of polypyrrole on aluminum and aluminum alloy by electron transfer mediation. J. Electrochem. Soc., 149, C173-C179. http://dx.doi.org/10.1149/1.1448820

Trabelsi, W., Cecilio, P., Ferreira, M. G. S., \& Montemor, M. F. (2005). Electrochemical assessment of the self-healing properties of Ce-doped silane solutions for the pre-treatment of galvanised steel substrates. Prog. Org. Coat., 54, 276-284. http://dx.doi.org/10.1016/j.porgcoat.2005.07.006

Trask, R. S., Williams, H. R., \& Bond, I. P. (2007). Self-healing polymer composites: mimicking nature to enhance performance. Bioinspiration \& Biomimetics, 2, 1-9. http://dx.doi.org/10.1088/1748-3182/2/1/P01

Uehara, K., Ichikawa, T., Serikawa, T., Yoshikawa, S., Ehara, S., \& Tsunooka, M. (1998). Redox reaction at the two-layer interface between aluminum and electropolymerized poly(3-methylthiophene) thin solid films. Thin Solid Films, 322, 198-205. http://dx.doi.org/10.1016/S0040-6090(97)00909-7

Yabuki, A., \& Sakai, M. (2011). Self-Healing Coatings of Inorganic Particles using a pH-Sensitive Organic Agent. Corros. Sci., 53, 829-833. http://dx.doi.org/10.1016/j.corsci.2010.11.021

Yabuki, A., Yamagami, H., \& Noishiki, K. (2007). Barrier and self-healing abilities of corrosion protective polymer coatings and metal powders for aluminum alloys. Mater. Corros., 58, 497-501. http://dx.doi.org/ 10.1002/maco.200604041

Zheludkevich, M. L., Serra, R., Montemor, M. F., \& Ferreira, M. G. S. (2005). Oxide nanoparticle reservoirs for storage and prolonged release of the corrosion inhibitors. Electrochem. Commun., 7, 836-840. http://dx.doi.org/10.1016/j.elecom.2005.04.039

Zheludkevich, M. L., Serra, R., Montemor, M. F., Yasakau, K. A., Salvado, I. M. M., \& Ferreira, M. G. S. (2005). Nanostructured sol-gel coatings doped with cerium nitrate as pre-treatments for AA2024-T3: Corrosion protection performance. Electrochim. Acta, 51, 208-217. http://dx.doi.org/10.1016/j.electacta.2005.04.021

\section{Copyrights}

Copyright for this article is retained by the author(s), with first publication rights granted to the journal.

This is an open-access article distributed under the terms and conditions of the Creative Commons Attribution license (http://creativecommons.org/licenses/by/3.0/). 